\title{
ON FORENSIC LINGUISTS AND NON-EXPERTS INTERPRETATION OF MULTIMODAL TEXTS ${ }^{1}$
}

\author{
Aleksandra V. Gorbacheva \\ Pushkin State Russian Language Institute, Moscow, Russia \\ Tatiana V. Nesterova \\ Pushkin State Russian Language Institute, Moscow, Russia \\ Mikhail A. Osadchiy \\ Pushkin State Russian Language Institute, Moscow, Russia
}

\begin{abstract}
The article presents intermediate results of an experimental research into psycholinguistic characteristics of understanding multimodal texts with extremist content. Forensic linguists specializing in extremism, well-informed and poorly informed in extremism discourse non-experts had to assess and comment upon multimodal texts. The peculiarities of interpretations have been established. The comprehension of sense in a multimodal text is constructed from established meanings of individual text components and detected semantic connections between them. Semantic and grammatical coordination of meanings of text components was the main mechanism of interpretation. The authors have performed the results of quantitative as well as qualitative analysis of experimental data using linguistic semantics methods. The indicators confirming the $\sum_{5}$ effectiveness of the expert assessment are given. The data presented confirm that forensic assessment of a multimodal text is influenced by presence or absence of both professional and general discourse knowledge. Both experts and non-experts have been proved to interpret multimodal texts using the semantic and grammatical coordination mechanisms. The correlation between these mechanisms and distorted text comprehension has $\varphi$ been established. The factors of non-forced expert mistakes have been determined as excessive habit of interpretation, predominance of expert experience in assessment of materials of a particular discourse and priming $\tilde{0} 0$ effect. The results of the study can be used to develop science-based methods and recommendations on methodology of forensic analysis of extremist texts for experts.

Key words: forensic linguistics, extremism, multimodal text, interpretation, comprehension, text and image, semantic coordination, grammatical coordination.
\end{abstract}

Citation. Gorbacheva A.V., Nesterova T.N., Osadchiy M.A. On Forensic Linguists and Non-Experts Interpretation of Multimodal Texts. Vestnik Volgogradskogo gosudarstvennogo universiteta. Seriya 2. Yazykoznanie [Science Journal of Volgograd State University. Linguistics], 2020, vol. 19, no. 1, pp. 102-114. (in Russian). DOI: https://doi.org/10.15688/jvolsu2.2020.1.9

\section{ОБ ЭКСПЕРТНОЙ И НЕЭКСПЕРТНОЙ ИНТЕРПРЕТАЦИИ ПОЛИКОДОВЫХ ТЕКСТОВ ${ }^{1}$}

\author{
Александра Вячеславовна Горбачева \\ Государственный институт русского языка им. А.С. Пушкина, г. Москва, Россия \\ Татьяна Вячеславовна Нестерова \\ Государственный институт русского языка им. А.С. Пушкина, г. Москва, Россия
}




\section{Михаил Андреевич Осадчий}

Государственный институт русского языка им. А.С. Пушкина, г. Москва, Россия

Аннотация. В статье представлены результаты промежуточного этапа экспериментального исследования психолингвистических особенностей понимания поликодовых текстов экстремистской направленности. Установлены особенности интерпретации текстов группами судебных экспертов-лингвистов и респондентов, хорошо или мало информированных о фактах экстремистского дискурса. Материал исследования включает оценки и комментарии контрольного и экспериментального стимульного материала. Представлены результаты анализа экспериментальных данных методами лингвистической семантики и количественного анализа. Приведены показатели, подтверждающие эффективность экспертной оценки. Выявлена значимость дискурсивных знаний для корректной интерпретации поликодового текста. Доказано, что эксперты и неэксперты интерпретируют тексты, используя механизмы семантического и грамматического согласования. Определена взаимосвязь между этими механизмами и возникновением искаженного понимания текста. Некорректные экспертные интерпретации экспериментального материала объясняются эффектом переобученности интерпретированию. Результаты представленного в работе исследования могут быть применены для разработки методических рекомендаций и научно обоснованной методики судебно-экспертного анализа поликодовых текстов.

Ключевые слова: судебная лингвистика, экстремизм, поликодовый текст, интерпретация, понимание, текст и изображение, семантическое согласование, грамматическое согласование.

Цитирование. Горбачева А. В., Нестерова Т. В., Осадчий М. А. Об экспертной и неэкспертной интерпретации поликодовых текстов // Вестник Волгоградского государственного университета. Серия 2, Языкознание. - 2020. - Т. 19, № 1. - С. 102-114. - DOI: https://doi.org/10.15688/jvolsu2.2020.1.9

\section{Введение}

Современная практика судебной лингвистической экспертизы показывает, что объектом исследования все чаще становится информация, представленная в семиотически сложных формах, таких как демотиваторы, мемы, страницы пользователей и сообществ в социальных сетях, песни, аудиокниги, подкасты, видеоклипы, фильмы, блоги и влоги. Интенсивная цифровизация всех режимов социального взаимодействия и рост доступности средств электронной коммуникации дает основания полагать, что в дальнейшем доля поликодовых текстов в объеме материалов, поступающих на судебную экспертизу, будет только увеличиваться, что обусловливает пристальное внимание к проблемам экспертной оценки таких объектов. В настоящий момент главная из них - это частотность расхождений в интерпретации смысла поликодовых текстов, факты которых регулярно фиксируются в рецензиях на экспертные заключения. Как представляется, указанная проблема связана с отсутствием единых научных подходов к методике анализа поликодовых текстов, учитывающих лингвистические, психолингвистические и психофизиологические закономерности их восприятия и понимания.
В данной статье описаны промежуточные результаты междисциплинарного экспериментального исследования, которое направлено на уточнение сведений о принципах интерпретации поликодовых текстов разными группами респондентов. Полученные данные могут быть применены для разработки научно обоснованной методики анализа текстов такого типа в экспертной деятельности лингвистов.

В отечественной традиции поликодовые тексты теоретически осмысляются начиная с середины 70-х годов [Ейгер, Юхт, 1974]. Российские исследователи концентрируют внимание на проблеме отношения вербальной и невербальной составляющих поликодовых текстов [Ариас, 2012; Вашунина, 2008], решают задачи по разработке алгоритмов интерпретации их отдельных жанров и дискурсов [Анисимова, 2003; Ариас, 2012; Ворошилова, 2013]. В последнее десятилетие изучение поликодовых текстов стало междисциплинарным направлением на стыке когнитивной психологии и лингвистики, вследствие чего на первый план вышли исследования закономерностей восприятия и понимания поликодовых текстов [Ворошилова, 2013; Злоказов, 2011; Сонин, 2006] и поиск методик анализа их содержания [Boрошилова, 2017]. 
В зарубежной традиции за три последние десятилетия, с начала интенсивной разработки этой темы в работах Г. Кресса и Т. ван Левена [Kress, Leeuwen, 1996], исследование поликодовых текстов (multimodalanalysis) превратилось в развитое направление с устойчивым репертуаром научных подходов. Значимыми для судебно-экспертной практики могут считаться выросшие из системно-функциональной лингвистики М. Халлидея [Halliday, 1978] социосемиотический [Kress, Leeuwen, 1996; 2001; Leeuwen, 2005] и системно-функциональный подходы к анализу поликодового дискурса (см., например: [Baldry, Thibault, 2006; O'Halloran, 2008]). В работах специалистов по социальной семиотике каталогизируются различные виды семиотических средств, принадлежащие к тому или иному дискурсу, а также разрабатывается грамматика образов, в том числе описываются значения, выражаемые физическими параметрами компонентов изображения (композиция, положение персонажей относительно адресата, направление их взглядов и др.). В рамках системно-функционального подхода поликодовый текст определяется как событие, результатом которого является отдельное специфическое значение, порождаемое во взаимодействии конкретных семиотических средств (semioticresources). Исследование и описание взаимодействия семиотических средств для получения специфической единицы информации составляет методологическую основу системно-функционального анализа поликодовых текстов. Достижения этих двух направлений, при условии дополнения их некоторыми положениями функциональной грамматики и лингвистической семантики, могут быть положены в основу разработки эффективного инструментария для анализа поликодовых текстов в судебно-экспертных целях.

\section{Методология и методика исследования}

Цель исследования - проверка гипотез о психолингвистических особенностях понимания семиотически неоднородной информации, а также выявление особенностей экспертного и неэкспертного понимания поликодовых текстов экстремистской направленности [Горбачева, Варламов, 2018; Горбачева, Пучкова, Осадчий,
2018; Пучкова, 2018]. В исследовании использовано понятие когнитивного концепта как единицы знания [Болдырев, Магировская, 2009; Сонин, 2006; Barsalou, 1992; Fodor, 1998]). Опираясь на традиционные представления нейрофизиологов и когнитивных психологов о принципах возникновения и хранения в памяти индивидуальных человеческих знаний о мире (см. обзор работ в [Горбачева, Варламов, 2018]), а также на новые экспериментальные данные о наборах контекстов, достаточных для реконструирования предмета речи [Pilatova, 2019], мы определили единицу знания как набор признаков репрезентируемого элемента реальности, который состоит из его регулярных и нерегулярных характеристики отношений с другими элементами реальности.

Основу методологии исследования составляют концепция системно-функционального подхода и положения лингвистики и психолингвистики о механизмах понимания смыслового содержания текста. Эти положения начали разрабатываться в лингвистике более шестидесяти лет назад [Косериу, 1969] и в своем современном состоянии формулируются в виде закона и правил семантического согласования: «Основной закон семантического сочетания слов сводится к тому, что для того, чтобы два слова составили правильное сочетание, они должны иметь, помимо специфических, различающих их сем, одну общую сему» [Гак, 1998, с. 279]; эти общие семы «итеративны, то есть в данном сообщении они встречаются неоднократно (по меньшей мере дважды), благодаря чему и осуществляют связь наименований на расстоянии... В такой итеративной функции может оказаться любая сема; мы будем называть ее ... «связующий семантический компонент» [Гак, 1998, с. 280]. Ю.Д. Апресян, уточняя положение о повторяемости сем, подчеркивает, что к правильному пониманию текста приводит выбор такого осмысления, «при котором повторяемость семантических элементов достигает максимума» [Апресян, 1995, с. 14].

В качестве материала исследования из российской судебно-экспертной практики были отобраны 30 текстов формата «статическое изображение + письменное высказывание», которые ранее были квалифицированы как содержащие лингвистические и психологи- 
ческие признаки различных типов правонарушений экстремистского характера в соответствии с методикой РФЦСЭ при Минюсте России [Кукушкина, Сафонова, Секераж, 2014]. Из их числа исключены тексты, не прошедшие проверку методом сходимости экспертных оценок внутри коллектива лингвистов. К 21 экспериментальному тексту подобраны контрольные тексты, аналогичные по количеству и степени сложности изобразительных знаков, не содержащие признаков правонарушений согласно действующему законодательству Российской Федерации.

В описываемой серии эксперимента приняло участие 42 человека. До начала эксперимента все участники были письменно проинформированы о том, что с целью проведения научного исследования им будут предъявляться материалы различного, в том числе экстремистского, характера. В эксперименте приняли участие респонденты, отличающиеся по степени осведомленности о содержании экстремистского дискурса, - группа судебных экспертов-лингвистов с опытом проведения исследований по материалам дел о противодействии экстремизму (11 человек) и группа неэкспертов, хорошо и мало информированных о фактах экстремистского дискурса (15 и 16 человек соответственно). Степень информированности устанавливалась посредством анкетирования респондентов, отвечавших в том числе на вопросы о том, насколько часто в повседневной жизни они сталкиваются с поликодовыми текстами формата «статическое изображение + письменное высказывание» и текстами экстремистского содержания.

В первой части эксперимента участникам в случайном порядке демонстрировались отобранные поликодовые тексты. При помощи последовательной демонстрации стимулов со сходным содержанием моделировалось влияние предшествовавшего контента на восприятие и понимание последующих стимулов (эффект прайминга [Солсо, 2006]) как фактор риска экспертной ошибки. После предъявления стимула респондентам предлагали оценить посредством возможных ответов «да», «нет», «затрудняюсь», является ли текст экстремистским, а затем дать структурированный устный комментарий, содержащий описание того, что видит испытуемый, и объяс- нение смысла увиденного. Респонденты не были ограничены во времени при просматривании стимула и обдумывании ответа. Объем комментария рекомендовалось ограничить тремя-пятью развернутыми высказываниями.

Во второй части эксперимента респондентам предлагалось найти и при помощи маркера обозначить в просмотренных текстах смысловые связи между изображением и письменным высказыванием, а также устно пояснить, в чем состоят взаимосвязи между элементами текста. Респонденты имели право сообщить, если обнаружить взаимосвязи не удавалось, и не комментировать текст. При разметке взаимосвязей ограничений во времени на обдумывание и в объеме комментария не устанавливалось. Запрет на выделение связей между элементами изображения также отсутствовал.

В ходе эксперимента комментарии респондентов фиксировались при помощи аудиозаписывающего устройства и в дальнейшем дословно расшифровывались. Впоследствии их содержание сопоставлялось и анализировалось с опорой на разметку взаимосвязей в стимулах методом компонентного анализа лексики комментариев. Если мнение респондента о смысле текста или отдельных его компонентов во второй части эксперимента изменялось, исследовался последний вариант интерпретации стимула.

\section{Результаты и обсуждение}

В таблице 1 представлены результаты оценки текстов, произведенной респондентами в первой части эксперимента.

Из приведенных данных видно, что при распределении оценок контрольных и экстремистских стимулов наблюдаются отличия как между различными группами респондентов, так и внутри групп. При оценке контрольных стимулов эксперты дали наибольшее количество верных ответов $(82,14 \pm 15,65 \%$ vs. $66,55 \pm 16,46 \%$ для хорошо информированных и $56,37 \pm 21,19 \%$ для мало информированных неэкспертов), допустили наименьшее ошибок $(11,51 \pm 11,06 \%$ vs. $19,80 \pm 11,29 \%$ и $15,92 \pm$ $10,85 \%$ соответственно), а также реже неэкспертов сомневались в оценке $(6,35 \pm 8,09 \%$ vs. $13,65 \pm 11,33 \%$ и $27,71 \pm 15,77 \%$ соответ- 


\section{Таблица 1. Оценка стимулов}

\section{Table 1. Stimuli assessment}

\begin{tabular}{|c|l|c|c|c|}
\hline Тип стимула & \multicolumn{1}{|c|}{ Группа респондентов } & $\begin{array}{c}\text { Кол-во верных } \\
\text { оценок стимула, \% }\end{array}$ & $\begin{array}{c}\text { Кол-во неверных } \\
\text { оценок стимула, \% }\end{array}$ & $\begin{array}{c}\text { Кол-во ответов } \\
\text { «затрудняюсь } \\
\text { оценить», \% }\end{array}$ \\
\hline \multirow{3}{*}{ Контрольные } & Эксперты & $82,14 \pm 15,65$ & $11,51 \pm 11,06$ & $6,35 \pm 8,09$ \\
\cline { 2 - 5 } & Хорошо информированные & $66,55 \pm 16,46$ & $19,80 \pm 11,29$ & $13,65 \pm 11,33$ \\
\cline { 2 - 5 } & Малоинформированные & $56,37 \pm 21,19$ & $15,92 \pm 10,85$ & $27,71 \pm 15,77$ \\
\hline \multirow{2}{*}{ Экстремистские } & Эксперты & $64,35 \pm 26,45$ & $19,57 \pm 17,89$ & $16,09 \pm 10,10$ \\
\cline { 2 - 5 } & Хорошо информированные & $63,00 \pm 25,12$ & $25,27 \pm 17,15$ & $11,72 \pm 11,24$ \\
\cline { 2 - 5 } & Малоинформированные & $61,59 \pm 24,29$ & $17,78 \pm 13,70$ & $20,63 \pm 23,60$ \\
\hline
\end{tabular}

ственно). Такие результаты могут объясняться наличием у экспертов специальных знаний, позволяющих критериально оценить контрольные тексты как не имеющие набора необходимых и достаточных признаков сообщения экстремистского характера. Испытуемые, хорошо информированные о содержании экстремистского дискурса, по сравнению с экспертами дали меньшее количество верных ответов $(66,55 \pm 16,46 \%$ для контрольных и $63,00 \pm$ $25,12 \%$ для экстремистских текстов), но ожидаемо опередили по этому показателю мало информированных респондентов $(56,37 \pm$ $21,19 \%$ и $61,59 \pm 24,29 \%$ соответственно). Большое количество правильных ответов у хорошо информированных неэкспертов можно объяснить степенью их осведомленности о фактах рассматриваемого дискурса. Тем не менее сравнение их результатов с экспертными показывает, что эти знания не всегда позволяют отличить экстремистский текст от текста, который не содержит признаков правонарушения. Об этом свидетельствует количество неверных ответов, данных хорошо информированными испытуемыми: оно выше, чем у остальных групп, для обоих типов стимулов, при этом количество ошибочных оценок в полтора-два раза превышает число затруднений в оценке. Вероятно, для респондентов этой группы значения, которые встречаются в экстремистском дискурсе, по причине их повторяемости становятся тривиальными и входят в зону бытовой нормы. Одновременно хорошо информированные неэксперты не владеют знаниями, которые позволяют диагностировать, какие наборы значений в сообщении делают его экстремистским, а какие нет. Это может объяснять, почему хорошо информированные неэксперты допускают большее количество ошибок при оценке как экст- ремистских, так и контрольных стимулов. Обратная ситуация наблюдается у мало информированных респондентов: они чаще остальных сообщали, что не понимают смысла текста, и отказывались от попытки однозначно оценить характер стимула $(27,71 \pm 15,77 \%$ для контрольных и 20,63 $\pm 23,60$ \% для экстремистских стимулов), за счет чего показатель ошибок в отношении экстремистских текстов у них даже ниже, чем у экспертов $(17,78 \pm 13,70 \%$ vs. $19,57 \pm 17,89)$, а в отношении контрольных стимулов он меньше, чем у хорошо информированных респондентов $(15,92 \pm 10,85 \%$ vs. $19,80 \pm 11,29 \%)$.

Картина оценок экстремистских стимулов отличается от картины по контрольным текстам прежде всего незначимыми различиями в количестве правильных ответов всех трех групп респондентов. Это может происходить вследствие того, что бо́льшая часть отобранных текстов характеризуется эксплицитным выражением экстремистского сообщения при помощи общеупотребительных семиотических средств. В свою очередь такая ясность сообщений соответствует коммуникативным целям пропаганды, поскольку успешность распространения идеи напрямую зависит от того, понятна ли она потенциальному адресату. Кроме того, абсолютное большинство респондентов имели неполное или полное высшее образование, что позволяет говорить о наличии у них сформированного навыка анализировать разнородную информацию. Обращают на себя внимание результаты экспертной оценки экстремистских стимулов. Так, в отношении экстремистских текстов эксперты сомневались чаще, чем по поводу контрольных, что с опорой на комментарии респондентов объясняется недостатком дискурсивных знаний и невозможностью воспол- 
нить его в условиях информационной изоляции в ходе эксперимента. Причиной сомнений также оказывалась совокупная недостаточность обнаруженных признаков для определения характера сообщения. В то же время возросло число ложноотрицательных оценок экстремистских стимулов, что может объясняться одновременным влиянием двух факторов недостаточностью диагностированных компонентов смысла текста для положительного вывода и действием этической пресуппозиции эксперта, которая в профессиональном кругу формулируется как «лучше не найти, чем найти». В целом интерпретация данных дает основание полагать, что для определения характера текста может оказаться значимым симультанное наличие дискурсивных и специальных знаний. Об этом также свидетельствуют результаты, полученные по отдельным стимулам, о которых речь пойдет ниже.

Приведенные в таблице 1 показатели фиксируют значительное отклонение по ответам отдельных респондентов от усредненного показателя оценок внутри их групп. Действительно, некоторые стимулы респонденты различных групп понимали и оценивали с существенными отличиями от средних величин (табл. 2).

Для выявления причин снижения успешности оценки был произведен анализ комментариев, относящихся к пяти стимулам, оценки которых характеризуются наибольшим отклонением от среднего. Ниже представлены результаты анализа на примере одного из этих стимулов (рисунок в табл. 2).

Используемый в качестве примера текст содержит призыв придерживаться граммати- ческих норм в письменной речи. Отправитель призыва - русскоязычные представители международного движения граммар-наци, которые позиционируют себя как сторонников соблюдения норм литературного языка, радикальных борцов за чистоту речи и используют визуальные аналогии с национал-социализмом, в том числе стилизацию буквы $\mathrm{G}$ под нацистскую свастику. Это значение текста было принято нами в качестве инварианта эталонной интерпретации. Анализируя количественные показатели оценки данного контрольного стимула, мы обратили внимание на резко возросшее число затруднений при квалификации этого текста у хорошо информированных и мало информированных неэкспертов $(50,00 \%$ vs. $13,65 \pm 11,33 \%$ и $40,00 \%$ vs. $27,71 \pm 15,77 \%$ соответственно). В то же время сомнения экспертов оказались близки к средним показателям для контрольных текстов $(8,33 \%$ vs. $6,35 \pm 8,09 \%)$, но значительно возросло число допущенных ими ошибок $(25,00 \%$ vs. $11,51 \pm 11,06 \%)$.

Сравнение результатов семантического анализа комментариев обеих частей эксперимента показало, что наряду с эталонной интерпретацией у респондентов возникло 7 повторяющихся неэталонных вариантов интерпретации этого стимула, которые представляют собой различные комбинации следующих четырех смыслов, присутствующих в ответах испытуемых всех групп: 1) пропаганда идеологии нацизма через визуальные отсылки к ней - цвета флага Третьего рейха, изображение нацистского офицера (присутствует в 33,3 \% неэталонных интерпретаций); 2) побуждение верно изображать представленный ис-

\section{Таблица 2. Пример стимула со значительным отклонением от среднего}

\section{Table 2. An example of stimuli with significant deviation from the mean value}

\begin{tabular}{|c|l|c|c|c|}
\hline Стимул & Группа респондентов & $\begin{array}{c}\text { Кол-во вер- } \\
\text { ных оценок } \\
\text { стимула, \% }\end{array}$ & $\begin{array}{c}\text { Кол-во невер- } \\
\text { ных оценок } \\
\text { стимула, \% }\end{array}$ & $\begin{array}{c}\text { Кол-во ответов } \\
\text { «затрудняюсь } \\
\text { оценить»\% }\end{array}$ \\
\hline \multirow{2}{*}{$\begin{array}{l}\text { Эксперты } \\
\text { Контрольный стимул }\end{array}$} & Хорошо информированные & 66,67 & 25,00 & 8,33 \\
\cline { 2 - 5 } & Малоинформированные & 26,67 & 14,29 & 50,00 \\
\hline
\end{tabular}


каженным символ нацизма - нацистскую свастику (присутствует в 65,2 \% неэталонных интерпретаций); 3) пропаганда идеологии нацизма через указание на Гитлера посредством символа $\mathrm{G}$ как его инициала и изображения нацистского офицера (присутствует в 33,3\% неэталонных интерпретаций); 4) побуждение вести себя «верно», то есть в соответствии с идеологией нацизма (присутствует в 12,5\% неэталонных интерпретаций).

Компонентный анализ лексики комментариев с опорой на разметку взаимосвязей в стимуле продемонстрировал, что эталонные и неэталонные варианты интерпретации коррелируют с ограниченными наборами установленных респондентами смысловых взаимосвязей, пересекающими по составу только частично.

При неэталонных интерпретациях и при отсутствии какой-либо интерпретации были обнаружены следующие взаимосвязи и соответствующие повторяющиеся в лексике комментариев семы, обусловливающие семантическое согласование: (1) изображение человека с атрибутами нацистского офицера / Гитлера - символ, сходный с нацистской свастикой (сема соотнесенности с нацизмом); (2) изображение человека с атрибутами нацистского офицера -использование цветов, форм и углов флага нацистской Германии (сема соотнесенности с нацизмом); (3) изображение человека с атрибутами нацистского офицера слово «ВЕРНО» (грамматическая сема образа действия + сема качества действия); (4) символ, сходный с нацистской свастикой использование цветов, форм и углов флага нацистской Германии (сема соотнесенности с нацизмом); (5) символ, сходный с нацистской свастикой - слово «ПИШИ»/ надпись «ПИШИ ВЕРНО» (грамматическая сема объекта воздействия); (6) буква $\mathrm{G}$, опознаваемая как инициал Гитлера -изображение человека с атрибутами нацистского офицера (грамматическая сема субъекта + сема имени субъекта); (7) неопознаваемый символ слово «ПИШИ» / надпись «ПИШИ ВЕРНО» (грамматическая сема отношения).

Варианты эталонной интерпретации включали семантические признаки, характерные для эталонных и неэталонных интерпретаций, и коррелируют со следующим набо- ром взаимосвязей и общих сем: (2) изображение человека с атрибутами нацистского офицера - использование цветов, форм и углов флага нацистской Германии (сема соотнесенности с нацизмом); (3) изображение человека с атрибутами нацистского офицера - слово «ВЕРНО» (грамматическая сема образа действия + сема качества действия); (7) неопознаваемый символ - слово «ПИШИ» / надпись «ПИШИ ВЕРНО» (грамматическая сема отношения); (8) символ граммар-наци - изображение человека с атрибутами офицера нацистской Германии (сема соотнесенности с нацизмом); (9) символ граммар-наци - использование цветов, форм и углов флага нацистской Германии (сема соотнесенности с нацизмом); (10) символ граммар-наци - слово «ПИШИ» / надпись «ПИШИ ВЕРНО» (сема группы лиц + сема объекта действия + сема образа действия); (11) надпись «ПИШИ ВЕРНО»изображение человека с атрибутами нацистского офицера (сема отправителя сообщения); (12) надпись «ПИШИ ВЕРНО» - изображение человека с атрибутами офицера нацистской Германии (сема угрозы наказания).

При сравнении наборов взаимосвязей эталонных и неэталонных интерпретаций обнаруживается различие в определении значения одного и того же символа. Все респонденты, которые неэталонно интерпретировали стимул или сообщили о невозможности его интерпретировать, во время эксперимента указали, что не осведомлены о значении изображенного символа. В то же время 94,7 \% респондентов с эталонной интерпретацией в комментариях информировали, что владеют информацией о движении граммар-наци. В таблице 3 показано распределение описанных смысловых взаимосвязей относительно эталонных (Э), неэталонных (НЭ) вариантов интерпретации и отсутствия интерпретации (0) с учетом фактора знания (+) / незнания (-) о движении граммар-наци.

Представленное распределение показывает, что варианты эталона обязательно включают взаимосвязь, построенную на знании характеристик движения граммар-наци и его соотношения с национал-социализмом. При этом неэталонные интерпретации складываются в результате комбинирования регуляр- 
A.В. Горбачева, Т.В. Нестерова, М.А. Осадчий. Об экспертной и неэкспертной интерпретации

\section{Таблица 3. Распределение смысловых взаимосвязей и фактор знания / незнания}

Table 3. The distribution of meaning correlation and awareness / lack of awareness factor

\begin{tabular}{|c|c|c|c|c|c|c|c|c|c|c|c|c|c|}
\hline \multirow{2}{*}{$\begin{array}{c}\text { № } \\
\text { участ- } \\
\text { ника } \\
\end{array}$} & \multirow{2}{*}{$\begin{array}{c}\text { Вариант } \\
\text { интерпре- } \\
\text { тации } \\
\end{array}$} & \multicolumn{12}{|c|}{$\begin{array}{c}\text { Выделенные взаимосвязанные компоненты } \\
\text { (компоненты с общей семой) }\end{array}$} \\
\hline & & (1) & (2) & (3) & (4) & (5) & (6) & (7) & (8) & (9) & (10) & (11) & (12) \\
\hline \multicolumn{14}{|c|}{ Эксперты } \\
\hline $06 \mathrm{fe}$ & НЭ & - & & & - & & & & & & & & \\
\hline $07 \mathrm{fe}$ & НЭ & & & & - & & & & & & & & \\
\hline $08 \mathrm{me}$ & НЭ & - & & & - & & & & & & & & \\
\hline $15 \mathrm{fe}$ & НЭ & - & & - & & & - & & & & & & \\
\hline $09 \mathrm{fe}$ & $Э$ & & & & & & & & + & & + & & \\
\hline $10 \mathrm{fe}$ & $Э$ & & & & & & & & + & + & + & & \\
\hline $19 \mathrm{fe}$ & $Э$ & & & & & & & & + & & + & & \\
\hline $22 \mathrm{me}$ & 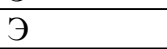 & & & & & & & & + & & + & + & \\
\hline $23 \mathrm{fe}$ & 3 & & & & & & & & & & + & & \\
\hline $24 \mathrm{fe}$ & 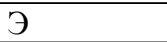 & & & + & & & & & + & & + & & \\
\hline $25 \mathrm{fe}$ & $\ni$ & & & & & & & & & & + & & + \\
\hline \multicolumn{14}{|c|}{ Хорошо информированные респонденты } \\
\hline $11 \mathrm{fc}$ & НЭ & & & & & & - & & & & & & \\
\hline $18 \mathrm{fc}$ & НЭ & - & & & & - & & & & & & & \\
\hline $21 \mathrm{mc}$ & НЭ & - & & & - & - & & & & & & & \\
\hline $35 \mathrm{fc}$ & НЭ & - & & & - & & - & & & & & & \\
\hline $42 \mathrm{fc}$ & НЭ & + & & & & & + & & & & + & & \\
\hline $17 \mathrm{mc}$ & 0 & - & & & & & & - & & & & & \\
\hline $20 \mathrm{fc}$ & 0 & - & & & & - & & & & & & & \\
\hline $34 \mathrm{fc}$ & 0 & - & & & & & & & & & & & \\
\hline $4 \mathrm{fc}$ & $Э$ & & & + & & & & & & & & & \\
\hline $12 \mathrm{fc}$ & $Э$ & & & & & & & & + & & + & & \\
\hline $13 \mathrm{mc}$ & $Э$ & & & + & & & & + & & & + & & \\
\hline $32 \mathrm{fc}$ & $Э$ & & & & & & & & & & + & & + \\
\hline $37 \mathrm{mc}$ & $\ni$ & & & & & & & & + & + & + & & \\
\hline $39 \mathrm{fc}$ & $Э$ & & & & & & & & + & + & + & & \\
\hline $40 \mathrm{mc}$ & Э & & & + & & & & & + & + & + & & \\
\hline \multicolumn{14}{|c|}{ Мало информированные респонденты } \\
\hline $26 \mathrm{fc}$ & НЭ & - & & & & - & & & & & & & \\
\hline $28 \mathrm{fc}$ & НЭ & & & & & - & - & & & & & & \\
\hline $29 \mathrm{fc}$ & НЭ & - & & - & & - & & & & & & & \\
\hline $30 \mathrm{fc}$ & НЭ & - & & - & & & & & & & & & \\
\hline $1 \mathrm{mc}$ & 0 & - & & & & & & & & & & & \\
\hline $2 \mathrm{fc}$ & 0 & & & & & & & & & & & & \\
\hline $16 \mathrm{fc}$ & 0 & & & & & & & - & & & & & \\
\hline $27 \mathrm{fc}$ & 0 & - & & & & & & & & & & & \\
\hline $33 \mathrm{fc}$ & 0 & & & & & & & & & & & & \\
\hline $36 \mathrm{fc}$ & 0 & - & & & & & & - & & & & & \\
\hline $41 \mathrm{fc}$ & 0 & & & & & & - & & & & & & \\
\hline $3 \mathrm{mc}$ & $Э$ & & + & & & & & & + & & + & + & \\
\hline $5 \mathrm{fc}$ & $\ni$ & & & & & & & & + & + & + & & + \\
\hline $14 \mathrm{fc}$ & $Э$ & & & & & & & & + & & + & & \\
\hline $31 \mathrm{fc}$ & $\ni$ & & + & + & & & & & & & + & & \\
\hline $38 \mathrm{mc}$ & $\ni$ & & & & & & & & + & & + & & \\
\hline
\end{tabular}

ных наборов взаимосвязей, в числе которых эта взаимосвязь отсутствует. Из этого следует, что понимание смысла поликодового текста является результатом верного или неверного установления выраженных значений и их взаимных отношений.
Неверное установление значения смыслообразующего компонента текста или невозможность его установить, как видно из таблицы 3 , не влечет, однако, принципиальной невозможности выстроить взаимосвязи, необходимые для наполнения текста каким-либо 
иным смыслом. Компонентный анализ лексики комментариев демонстрирует, что недостаток эталонных семантических связей при попытке понять текст компенсируется заполнением пустующих грамматических (синтаксических) валентностей и наложением на образующиеся грамматические связи случайных семантических повторов. Так, в ряде неэталонных интерпретаций «ПИШИ» с незаполненной объектной валентностью и неэталонно опознаваемый символ дают значение 'пиши символ'. С опорой на вновь возникшую синтаксическую конструкцию «ВЕР$\mathrm{HO}$ » $(\mathrm{A}+)$, семантически противоположное 'неверно, неправильно' (А-), по семе 'правильность' получает случайное семантическое согласование с символом $\mathrm{G}$, который в действительности связан с нацистской свастикой только смысловыми отношениями отличности по форме, но по причине навязанного значения объекта воздействия оказывается семантической мишенью для слова «ВЕРНО» и единовременно приобретает комплект взаимосвязанных значений 'неправильность формы' и 'нацистская свастика'. В других вариантах интерпретации сирконстант «ВЕРНО» по повтору грамматической семы образа действия связывается с изображением нацистского офицера как с отсылкой к доктринам национал-социализма, и таким образом респонденты обнаруживают в стимуле положительную оценку идеологии нацизма. Это соотносится с закономерностью реализации грамматического согласования, отмеченной Ю.Д. Апресяном: «А, грамматически согласованное с $\mathrm{B}$, заимствует у последнего определенные значения в данном тексте», в то время как «семантически согласованные друг с другом слова Л и В не приобретают общие смысловые элементы в тексте, а имеют их еще в словаре» [Апресян, 1995, с. 14].

Наш пример показывает, что существует возможность обнаружения грамматической взаимосвязи между семантически не связанными компонентами поликодового текста за счет приписывания одному из них «чужих» категориальных значений, что в дальнейшем может служить основой для наращения изначально отсутствующей семантики. Таким образом, взаимодействие речевого и изобразительного компонентов так или иначе построено на наличии повторяющейся семы, которая заполняет либо семантическую, либо грамматическую валентности.

В ходе исследования было выявлено, что заполнение грамматических валентностей и наращение семантики характерно для неэталонных интерпретаций независимо от фактора принадлежности респондентов к какой-либо из групп. При этом ключевую роль в запуске этого механизма играет, судя по всему, фактор информационной недостаточности, который, однако, не гарантирует формирования законченного варианта интерпретации. В приведенной выборке содержатся ответы хорошо и мало информированных неэкспертов, которые испытали информационную недостаточность при интерпретации стимула, предприняли попытку установить взаимосвязи компенсаторным способом, но не сумели обнаружить достаточного количества смысловых повторов для построения результирующего концепта (число обнаруженных взаимосвязей в этих случаях не превышает двух, а если уже достигнуто, то семантический повтор обнаруживается вне найденной грамматической взаимосвязи). В нашем примере это может свидетельствовать о том, что неэксперты и эксперты отличаются друг от друга не только наличием / отсутствием специальных знаний, но и опытом выявления взаимосвязей для получения целостного понимания текста. Именно с этим может быть связана высокая степень уверенности в оценке текста экспертами. Механизм компенсации информационной недостаточности может оказаться одной из причин экспертных ошибок наряду с возможностью ошибки подтверждения - разновидности когнитивного искажения, обусловленной преобладанием экспертного опыта в конкретной области [Nickerson, 1998] и/или эффектом прайминга, смоделированного в рамках этого эксперимента.

Представляется, что дальнейшее изучение рассмотренных выше механизмов интерпретации и предполагаемых причин добросовестных экспертных заблуждений может способствовать повышению объективности экспертных оценок и сокращению числа невынужденных ошибок. 


\section{Выводы}

Результаты представленного экспериментального исследования подтверждают и уточняют наши предположения о принципах и механизмах понимания поликодовых текстов: 1) понимаемый смысл поликодового текста - это значение, которое конструируется в результате установления значений отдельных компонентов текста (независимо от формы их выражения) и обнаружения смысловых взаимосвязей между ними; 2) такие взаимосвязи образуются при помощи повторения общих сем и являются реализацией грамматического и/или семантического согласования; 3 ) на возможность корректно интерпретировать поликодовый текст в рамках определенного дискурса влияет наличие / отсутствие дискурсивных знаний; на возможность дать специальную оценку этому тексту - одновременное наличие / отсутствие дискурсивных и специальных знаний; 4) эксперты и неэксперты интерпретируют поликодовые тексты, используя механизм семантического и грамматического согласования; в отличие от неэкспертов эксперты могут испытывать эффект переобученности интерпретированию, а также допускать ошибки в связи с преобладанием экспертного опыта в оценке материалов отдельного дискурса и/или с связи с эффектом прайминга.

Приведенные результаты при расширении выборки могут корректироваться. В настоящем виде они могут быть использованы при разработке методики анализа поликодовых текстов для судебных экспертов в целях предотвращения экспертных ошибок и оптимизации трудовых процессов при производстве судебных экспертиз.

\section{ПРИМЕЧАНИЯ}

${ }^{1}$ Работа выполнена при финансовой поддержке РФФИ, проект № 17-29-09170 «Исследование психофизиологических и психолингвистических особенностей восприятия и декодирования поликодовых текстов экстремистской направленности».

The Reported Study Was Funded by RFBR, Project no. 17-29-09170 "Psychophysical and Psycholinguistic Assessment of Perception and Decoding of Multimodal Texts of Extremist Nature".

\section{СПИСОК ЛИТЕРАТУРЫ}

Анисимова Е. Е., 2003. Лингвистика текста и межкультурная коммуникация (на материале креолизованных текстов). М. : Academia. $122 \mathrm{c}$.

Апресян Ю. Д., 1995. Избранные труды. В 2 т. Т. 1. Лексическая семантика (синонимические средства языка). 2-е изд., испр. и доп. М. : Яз. рус. культуры ; Восточ. лит. VIII, 472 с.

Ариас А.-М., 2012. Взаимодействие вербального и невербального компонентов в карикатуре и коллаже (на материале немецкоязычных СМИ) : дис. ... канд. филол. наук. СПб. $179 \mathrm{c}$.

Болдырев Н. Н., Магировская О. В., 2009. Языковая репрезентация основных уровней познания // Вопросы когнитивной лингвистики. № 2. C. 7-16.

Вашунина И. В., 2008. Особенности оценки креолизованного текста в зависимости от параметров иллюстрации // Вестник Нижегородского университета им. Н.И. Лобачевского. № 4. C. 223-227.

Ворошилова М. Б., 2013. Политический креолизованный текст: ключи к прочтению. Екатеринбург : Урал. гос. пед ун-т. 194 с.

Ворошилова М. Б., 2017. Методология, методы и методики анализа креолизованного текста // Эволюция лингвистической экспертизы. Методы и приемы : монография. Екатеринбург : Урал. гос. пед ун-т. С. 125-199.

Гак В. Г., 1998. Языковые преобразования. М. : Шк. «Яз. рус. культуры». 768 с.

Горбачева А. В., Варламов А. А., 2018. О гипотетической модели восприятия и понимания поликодовых текстов // Международный аспирантский вестник. Русский язык за рубежом. № 4. С. 66-73.

Горбачева А. В., Пучкова А. Н., Осадчий М. А., 2018. $\mathrm{O}$ принципах понимания и семантических правилах интерпретации знаков в изобразительной части поликодовых текстов // Ученые записки УО «ВГУ им. П.М. Машерова». Т. 27. C. 53-57.

Ейгер Г. В., Юхт В. Л., 1974. К построению типологии текстов // Лингвистика текста : материалы науч. конф. В 2 ч. Ч. 1. М. С. 103-110.

Злоказов К. В., 2011. Анализ особенностей восприятия креолизованного текста деструктивноэкстремистской направленности // Политическая лингвистика. Т. 3, № 37. С. 210-216.

Косериу Э., 1969. Лексические солидарности // Вопросы учебной лексикографии / под ред. П. Н. Денисова, Л. А. Новикова. М. : Изд-во МГУ. С. 93-104. 
Кукушкина О. В., Сафонова Ю. А., Секераж Т. Н., 2014. Методика проведения судебной психолого-лингвистической экспертизы материалов по делам, связанным с противодействием экстремизму и терроризму. М. : Изд-во ФБУ РФЦСЭ при Минюсте России. 98 с.

Пучкова А. Н., 2018. Шаблоны восприятия цифровых поликодовых текстов экстремистской направленности и перспективы их экспериментального исследования // Международный аспирантский вестник. Русский язык за рубежом. № 4. С. 74-79.

Солсо Р., 2006. Когнитивная психология. 6-е изд. СПб. : Питер. 589 с.

Сонин А. Г., 2006. Моделирование механизмов понимания поликодовых текстов : дис. ... д-ра филол. наук. М. 323 с.

Baldry A., Thibault P. J., 2006. Multimodal Transcription and Text Analysis: A Multimedia Toolkit and Associated On-line Coursebook. L. ; Oakville: Equinox. 270 p.

Barsalou L. W., 1992. Frames, Concepts, and Conceptual Fields // Frames, Fields, and Contrasts / ed by A. Lehrer, E. F. Kittay. Hillsdale, New Jersey : Lawrence Erlbaum Associates. P. 21-74.

Fodor J. A., 1998. Concepts: Where Cognitive Science Went Wrong. Oxford : Oxford University Press. $174 \mathrm{p}$.

Halliday M. A. K., 1978. Language As a Social Semiotic: The Social Interpretation of Language and Meaning. Baltimore : University Park Press. $256 \mathrm{p}$.

Kress G., Leeuwen T. van, 1996. Reading Images: The Grammar of Visual Design. N. Y. : Routledge. $312 \mathrm{p}$.

Kress G., Leeuwen T. van, 2001. Multimodal Discourse: The Modes and Media of Contemporary Communication. L. : Edward Arnold. 152 p.

Leeuwen T. van, 2005. Introducing Social Semiotics. N. Y. : Psychology Press. 320 p.

Nickerson R. S., 1998. Confirmation Bias: A Ubiquitous Phenomenon in Many Guises // Review of General Psychology. Vol. 2, iss. 2. P. 175-220. DOI: 10.1037/1089-2680.2.2.175.

O’Halloran K., 2008. Systemic Functional-Multimodal Discourse Analysis (SF-MDA): Constructing Ideational Meaning Using Language and Visual Imagery// Visual Communication. Vol. 7, iss. 4. P. 443-475. DOI: 10.1177/1470357208096210.

Pilatova O. I., 2019. Conventional Lexical Means for Representation of Semantics of Concepts (Evidence from Russian Language) // Neurobiology of Speech and Language. Proceedings of the $3^{\text {rd }}$ International Conference «Neurobiology of Speech and Language». Saint Petersburg : Skifiya-print. P. 51-52.

\section{REFERENCES}

Anisimova E.E., 2003. Lingvistika teksta $i$ mezhkulturnaya kommunikatsiya (na materiale kreolizovannykh tekstov) [Linguistics of the Text and Intercultural Communication (Based on Multimodal Texts)]. Moscow, Academia Publ. 122 p.

Apresyan Yu.D., 1995. Izbrannye trudy. V 2 t. T. 1. Leksicheskaya semantika (sinonimicheskie sredstva yazyka) [Selected Works. In 2 Vols. Vol. 1. Lexical Semantics (Synonymous Means of Language]. Moscow, Yazyki russkoy kultury Publ., Vostochnaya literature Publ., VIII. 472 p.

Arias A.-M., 2012. Vzaimodeystvie verbalnogo $i$ neverbalnogo komponentov $v$ karikature $i$ kollazhe (na materiale nemetskoyazychnykh SMI): dis. ... kand. filol. nauk [Interaction of Verbal and Nonverbal Components in Caricature and Collage (Based on German-Language Media). Cand. philol. sci. diss.]. Saint Petersburg. $179 \mathrm{p}$.

Boldyrev N.N., Magirovskaya O.V., 2009. Yazykovaya reprezentatsiya osnovnykh urovney poznaniya [Language Representation of Main Cognitive Levels]. Voprosy kognitivnoy lingvistiki [Issues of Cognitive Linguistics], no. 2 (19), pp. 7-16.

Vashunina I.V., 2008. Osobennosti otsenki kreolizovannogo teksta $\mathrm{v}$ zavisimosti ot parametrov illyustratsii [Peculiarities of Creolized Text Evaluation Depending on Illustration Parameters]. Vestnik Nizhegorodskogo universiteta im. N.I. Lobachevskogo [Vestnik of Lobachevsky University of Nizhni Novgorod], no. 4, pp. 223-227.

Voroshilova M.B., 2013. Politicheskiy kreolizovannyy tekst: klyuchi k prochteniyu [Political Creolized Text: Keys to Reading]. Yekaterinburg, Uralskiy gosudarstvennyy pedagogicheskiy universitet. $194 \mathrm{p}$.

Voroshilova M.B., 2017. Metodologiya, metody i metodiki analiza kreolizovannogo teksta [Methodology, Methods, and Methodics of Analysis of Creolized Texts]. Evolyutsiya lingvisticheskoy ekspertizy. Metody i priemy: monografiya [Evolution of Linguistic Expertise. Methods and Techniques. Monograph]. Yekaterinburg, Uralskiy gosudarstvennyy pedagogicheskiy universitet, pp. 125-199.

Gak V.G., 1998. Yazykovye preobrazovaniya [Language Eransformations]. Moscow, Shkola «Yazyki russkoy kultury». $768 \mathrm{p}$.

Gorbacheva A.V., VarlamovA.A., 2018. Ogipoteticheskoy modeli vospriyatiya i ponimaniya polikodovykh tekstov [On the Hypothetical Model of Perception and Comprehension of Polycode Texts]. 
Mezhdunarodnyy aspirantskiy vestnik. Russkiy yazyk za rubezhom [Russian Language Abroad], no. 4,pp. 66-73.

Gorbacheva A.V., Puchkova A.N., Osadchiy M.A., 2018. O printsipakh ponimaniya i semanticheskikh pravilakh interpretatsii znakov v izobrazitelnoy chasti polikodovykh tekstov [On Principals of Perception and Semantic Laws of Sign Interpretation in Descriptive Part of Polycode Texts]. Uchenye zapiski $U O$ " $V G U$ im. P.M. Masherova”, vol. 27, pp. 53-57.

Eyger G.V., Yukht V.L., 1974. K postroeniyu tipologii tekstov [On the Construction of Text Typology]. Lingvistika teksta: materialy nauch. konf. $V 2$ ch. Ch. 1 [Text Linguistics. Proceedings of the Scientific Conference. In 2 Parts. Part 1]. Moscow, pp. 103-110.

Zlokazov K.V., 2011. Analiz osobennostey vospriyatiya kreolizovannogo teksta destruktivnoekstremistskoy napravlennosti [Analysis of Perception Peculiarities of a Creloized Text of a Distructive Extremist Trend]. Politicheskaya lingvistika [Political Linguistics], vol. 3, no. 37, pp. 210-216.

Coseriu E., 1969. Leksicheskie solidarnosti [Lexical Solidarity]. Denisov P.N., Novikova L.A., eds. Voprosy uchebnoy leksikografii [Issues of Educational Lexicography]. Moscow, Izd-vo MGU, pp. 93-104.

Kukushkina O.V., Safonova Yu.A., Sekerazh T.N., 2014. Metodika provedeniya sudebnoy psikhologolingvisticheskoy ekspertizy materialov po delam, svyazannym s protivodeystviem ekstremizmu i terrorizmu [Methods of Conducting Forensic Psychological and Linguistic Examination of Materials on Cases Related to Countering Extremism and Terrorism]. Moscow, Izd-vo FBU RFTsSE pri Minyuste Rossii. 98 p.

Puchkova A.N., 2018. Shablony vospriyatiya tsifrovykh polikodovykh tekstov ekstremistskoy napravlennosti i perspektivy ikh eksperimentalnogo issledovaniya [Perception Patterns of Extremist Polycode Texts end The Perspectives of Their Experimental Research]. Mezhdunarodnyy aspirantskiy vestnik. Russkiy yazyk za rubezhom [Russian LanguageAbroad], no. 4, pp. 74-79.
Solso R., 2006. Kognitivnaya psikhologiya [Cognitive Psychology]. Saint Petersburg, Piter Publ. 589 p.

Sonin A.G., 2006. Modelirovanie mekhanizmov ponimaniya polikodovykh tekstov: dis. ... d-ra filol. nauk [Modeling of Mechanisms for Understanding Multimodal Texts. Dr. philol. sci. diss.]. Moscow. 323 p.

Baldry A., Thibault P.J., 2006. Multimodal Transcription and Text Analysis: A Multimedia Toolkit and Associated On-Line Coursebook. London, Oakville, Equinox. 270 p.

Barsalou L.W., 1992. Frames, Concepts, and Conceptual Fields. Lehrer A., Kittay E.F., eds. Frames, Fields, and Contrasts. Hillsdale, New Jersey, Lawrence Erlbaum Associates, pp. 21-74.

Fodor J.A., 1998. Concepts: Where Cognitive Science Went Wrong. Oxford, Oxford University Press. $174 \mathrm{p}$.

Halliday M.A.K., 1978. Language as a Social Semiotic: The Social Interpretation of Language and Meaning. Baltimore, University Park Press. 256 p.

Kress G., Leeuwen T. van, 1996. Reading Images: The Grammar of Visual Design. New York, Routledge. $312 \mathrm{p}$.

Kress G., van Leeuwen T., 2001. Multimodal Discourse: The Modes and Media of Contemporary Communication. London, Edward Arnold. 152 p.

Leeuwen T. van, 2005. Introducing Social Semiotics. New York, Psychology Press. 320 p.

Nickerson R.S., 1998. Confirmation Bias: A Ubiquitous Phenomenon in Many Guises. Review of General Psychology, vol. 2, iss. 2, pp. 175-220. DOI:10.1037/1089-2680.2.2.175.

O’Halloran K., 2008. Systemic Functional-Multimodal Discourse Analysis (SF-MDA): Constructing Ideational Meaning Using Language and Visual Imagery. Visual Communication, vol. 7, iss. 4, pp. 443-475. DOI: 10.1177/1470357208096210.

Pilatova O.I., 2019. Conventional Lexical Means for Representation of Semantics of Concepts (Evidence from Russian Language). Neurobiology of Speech and Language. Proceedings of the 3rd International Conference "Neurobiology of Speech and Language». Saint Petersburg, Skifiya-print, pp. 51-52. 


\section{Information about the Authors}

Aleksandra V. Gorbacheva, Chief Expert, Center for Cognition and Communication, Pushkin State Russian Language Institute, Akademika Volgina St., 6, 117485 Moscow, Russia, avgorbacheva@pushkin.institute, https://orcid.org/0000-0002-8906-3870

Tatiana V. Nesterova, Candidate of Sciences (Philology), Associate Professor, Professor, Department of General and Russian Linguistics, Pushkin State Russian Language Institute, Akademika Volgina St., 6, 117485 Moscow, Russia, tvnesterova@pushkin.institute, https://orcid.org/0000-0002-1799-1897

Mikhail A. Osadchiy, Doctor of Sciences (Philology), Professor, Department of General and Russian Linguistics, Vice-Rector for Science, Pushkin State Russian Language Institute, Akademika Volgina St., 6, 117485 Moscow, Russia, maosadchiy@pushkin.institute, https://orcid.org/0000-0001-7964-9029

\section{Информация об авторах}

Александра Вячеславовна Горбачева, главный эксперт научного центра нейрокоммуникативных исследований, Государственный институт русского языка им. А.С. Пушкина, ул. Академика Волгина, 6, 117485 г. Москва, Россия, avgorbacheva@pushkin.institute, https://orcid.org/0000-0002-8906-3870

Татьяна Вячеславовна Нестерова, кандидат филологических наук, доцент, профессор кафедры общего и русского языкознания, Государственный институт русского языка им. А.С. Пушкина, ул. Академика Волгина, 6, 117485 г. Москва, Россия, tvnesterova@pushkin.institute, https://orcid.org/0000-0002-1799-1897

Михаил Андреевич Осадчий, доктор филологических наук, профессор кафедры общего и русского языкознания, проректор по науке, Государственный институт русского языка им. А.С. Пушкина, ул. Академика Волгина, 6, 117485 г. Москва, Россия, maosadchiy@pushkin.institute, https://orcid.org/0000-0001-7964-9029 